\title{
Distribution and Structure of Purkinje Fibers in the Heart of Ostrich (Struthio camelus) with the Special References on the Ultrastructure
}

\author{
Paria Parto, ${ }^{1}$ Mina Tadjalli, ${ }^{2}$ S. Reza Ghazi, ${ }^{2}$ and Mohammad Ali Salamat ${ }^{3}$ \\ ${ }^{1}$ Biological Department, Faculty of Science, Razi University, Kermansha 6714967346, Iran \\ ${ }^{2}$ School of Veterinary Medicine, Shiraz University, Shiraz 1731-71345, Iran \\ ${ }^{3}$ Biological Department, Faculty of Science, Razi University, Kermansha 6714967346, Iran \\ Correspondence should be addressed to Paria Parto; pariaparto@gmail.com
}

Received 20 May 2013; Revised 29 July 2013; Accepted 29 July 2013

Academic Editor: Greg Demas

Copyright (c) 2013 Paria Parto et al. This is an open access article distributed under the Creative Commons Attribution License, which permits unrestricted use, distribution, and reproduction in any medium, provided the original work is properly cited.

Purkinje fibers or Purkinje cardiomyocytes are part of the whole complex of the cardiac conduction system, which is today classified as specific heart muscle tissue responsible for the generation of the heart impulses. From the point of view of their distribution, structure and ultrastructural composition of the cardiac conduction system in the ostrich heart were studied by light and electron microscopy. These cells were distributed in cardiac conducting system including SA node, AV node, His bundle and branches as well as endocardium, pericardium, myocardium around the coronary arteries, moderator bands, white fibrous sheet in right atrium, and left septal attachment of AV valve. The great part of the Purkinje fiber is composed of clear, structure less sarcoplasm, and the myofibrils tend to be confined to a thin ring around the periphery of the cells. They have one or more large nuclei centrally located within the fiber. Ultrastructurally, they are easily distinguished. The main distinction feature is the lack of electron density and having a light appearance, due to the absence of organized myofibrils. P-cells usually have two nuclei with a mass of short, delicate microfilaments scattered randomly in the cytoplasm; they contain short sarcomeres and myofibrillar insertion plaque. They do not have T-tubules.

\section{Introduction}

Jan Evangelista Purkinje was born on 18 December, 1787, in Libochovice (Bohemia). Between the ages of 35 and 63, he made his most significant discoveries. This very age generally displays the physiological measure of the biggest creative waves of the human being. From 1850 until his death in 1869, Purkinje worked in the Institute of Physiology in Prague, which he had based. The acquisition of the big Plösl microscope in 1835 represented an important turning point for Purkinje's histological and embryological research. Purkinje published his discovery of a part of the heart conduction system, nowadays called Purkinje fibers or Purkinje cardiomyocytes [1].

Tawara (1906) was able to follow proximally from the Purkinje fibers (P-fiber) to the besides bundles, which, he organize, were connected to his bundle. Afterwards, he found that his bundle was connected proximally to a wellset plexus of fibers (which he called a node, in his book).
This is the arterioventricular node. In addition, he was able to display interdigitating connections between the Purkinje fibers and ventricular muscles, as well as between the node and arterial muscles [2]. Electrical activity of the specialized conducting system of canine hearts has been recorded in situ through electrodes attached to the endocardium during total cardiopulmonary bypass [3]. Armiger et al. [4] stated that the connective tissue of the trabeculae got from the puppies and the young dogs had little elastic fibers, but this element was well extended in the connective tissue of the adult dogs. The trabeculae of older dogs also showed distributed foci of extracellular fat droplets, and their junctional areas nearest to the ventricular wall were often heavily full with fat. The Purkinje cells were uniform in each group but differed from one group to another [4].

Forsgren et al. [5] identified that in the bovine fetal heart subendocardial bundles of cells could be prominent from the main myocardial mass. Their morphological characteristics 


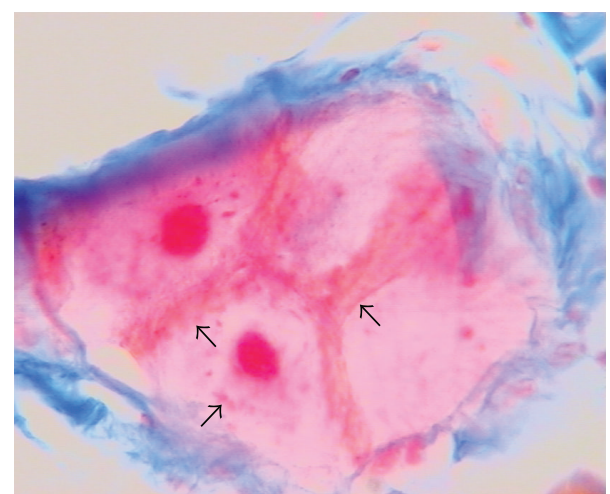

Figure 1: Photomicrograph from the microscopic location of the Purkinje cell in the endocardial layer of the sinus venosus of left sinus-arterial valve in the male ostrich heart. Arrow-myofibril cells.

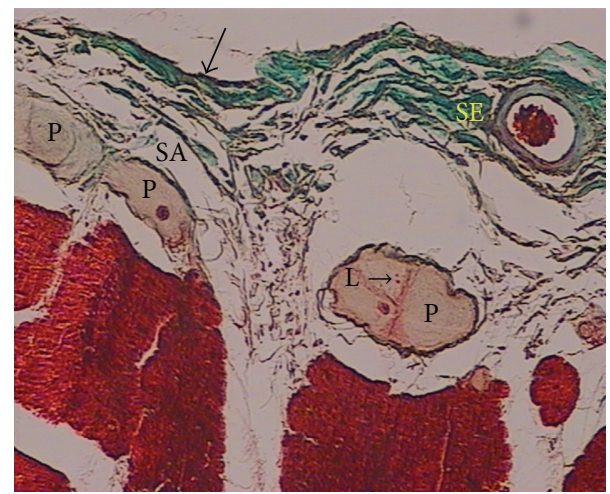

FIgURe 2: Photomicrograph from the microscopic location of the Purkinje fibers in endocardium, that showing the layers, Green Masson's Trichrome. Arrow-endothelium cells, SE-subendothelium layer, SA-subendocardial, P-Purkinje cell, ${ }^{*}$ - connective tissue sheath, $\mathrm{M}-$ myocardial cells, $\mathrm{L}-$ lipofuscin pigment.

express that they represent bundles of Purkinje fibers. A severe fluorescence after incubation in antisera up to the intermediate filament protein skeleton is also backing this suggestion [5].

A comparative ultrastructural study of bovine Purkinje fibers and common myocytes during fetal development has been undertaken by Forsgren and Thornell [6].

Differences between the two cell types with respectability to the accommodated disc, amount of myofibrils, sequence of mitochondria, amount of glycogen, and formation of Ttubules became apparent gradually. In all stages studied, a redundancy of intermediate filaments was typical for the Purkinje fibers. Myofibrillar M-bands developed an earlier stage in Purkinje fibres than in ordinary myocytes. Myofilament-polyribosome complexes typical of adult cow Purkinje fibers were not seen in the fetal hearts [6].

The ostrich heart has some different features from the other birds. In the ostrich, fibrous pericardium as sternopericardial ligament attaches along the thoracic surface of the sternum. The central edge of muscular valve hangs down into

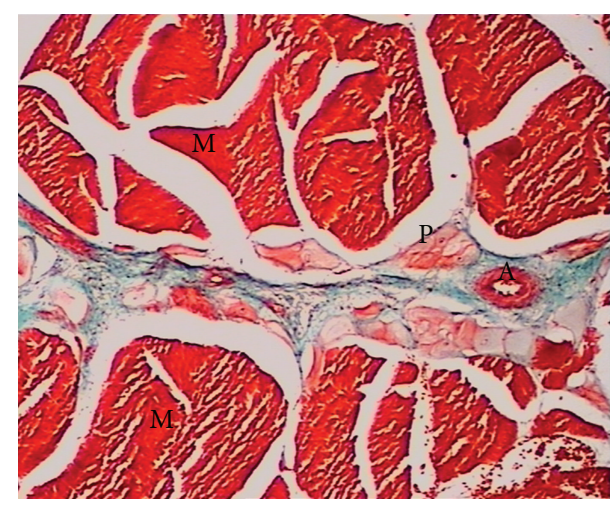

FIgURE 3: Photomicrograph from the microscopic location of the Purkinje fibers $(\mathrm{P})$ around coronary artery $(\mathrm{A})$, between the heart muscle bundles, (M) Green Masson's Trichrome.

the right ventricle and gives attachment to its rough parietal wall by a thick muscular stalk. The left and right pulmonary veins enter the left atrium independently, and their openings were completely separated from each other by a septum. In the heart of the ostrich, the moderator bands were found in both the right and left ventricles in different locations. The right ventricle presents one tendinous moderator band near the base of the ventricle that extends from septum to the muscular valve. Also the moderator bands as tendinous thread like or flat sheet are usually present at about apex of the right ventricle that extends from septum to the parietal wall. In the left ventricle, there were some tendinous moderator bands close to the apex that extends from septum to the parietal wall and between trabeculae carneae of the parietal wall [7].

Cardiovascular diseases in human and animals are one of the main causes of death. Thus, correct interpretation of heart function or physiology needs full understanding of anatomy, histology, and cardiac conduction system. Macroscopic and microscopic anatomy of heart and its conduction system has been studied in several animal species, but there is no comprehensive research on the ostrich (Struthio camelus) heart. The results of this survey in future will be used as basic knowledge.

\section{Materials and Methods}

2.1. Light Microscopy. Five hearts from healthy male ostriches were used. The hearts were collected at the slaughter house immediately after slaughter. The average weight of the hearts was $1054.33 \pm 172.34 \mathrm{~g}$; the length of the long axis was 19.33 $\pm 1.05 \mathrm{~cm}$; and the circumferential length at the coronary groove was $35.66 \pm 1.04 \mathrm{~cm}$. After removal of pericardium, the hearts were flushed with normal saline and subsequently immersed in $10 \%$ buffer neutral formalin for $72 \mathrm{hrs}$ (ventricular apex was cut off to permit the penetration of formalin into the lumen). The right and left atrium, right muscular valve, and interarterial septum were separated and divided into several segments. Each segment was dehydrated, cleared, and embedded in paraffin. Serial sections of 6-8 Lm 


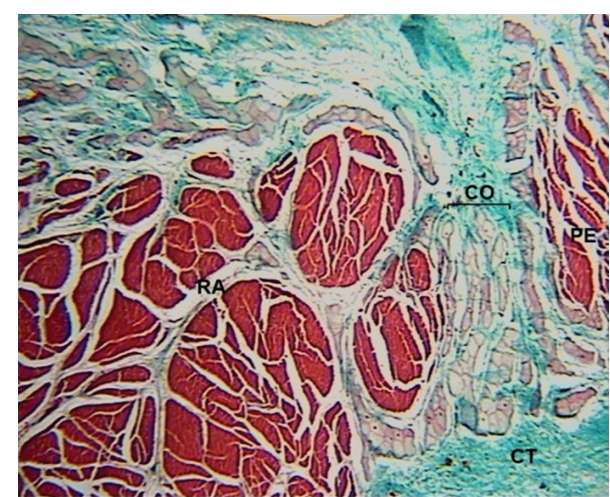

(a)

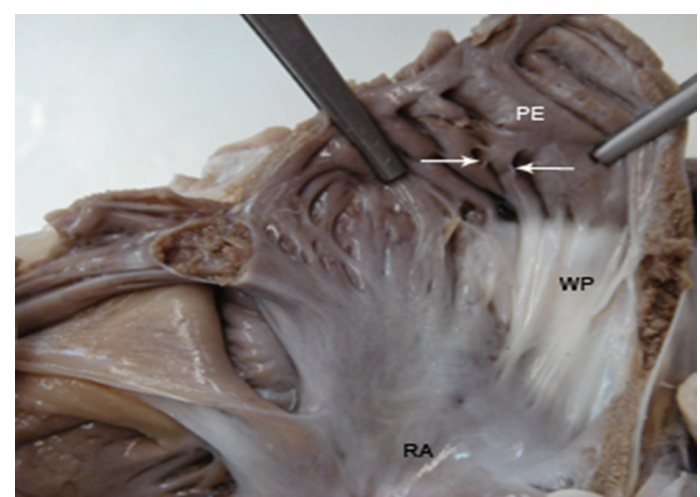

(b)

Figure 4: (a) Photomicrograph from the microscopic location of the fibrous white sheet in between the pectinate muscles (PE), in the right atrium (RA) in the male ostrich heart. Green Masson's Trichrome: CT-connective tissue mass, CO-columns of Purkinje cells. (b) Photomicrograph from the microscopic location of the fibrous white sheet (WP) and related clauses (arrow) in right atrium the male ostrich heart: RA-right atrium bottom, PE-shoulder muscles.

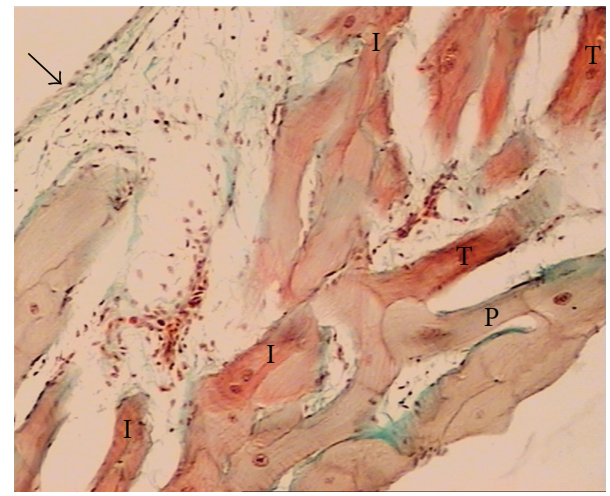

FIgURE 5: Photomicrograph from the microscopic location of the sinoatrial node (SAN), showing P cells (P), transitional cells (T), and intermediate (I). Arrow-endothelial cells in surface sinuatrial valve of the sinus venosus, Green Masson's Trichome.

thickness were cut, mounted, and stained with H\&E and Green Masson's Trichrome [8].

2.2. Electron Microscopy. Three other hearts were removed just after slaughter and quickly immersed in Karnovsky's solution for fixation. Cubes of tissue (about $1 \mathrm{~mm}$ ) were post-fixed in $1 \%$ osmium tetroxide with $0.1 \mathrm{~m}$ phosphate buffer. Specimens were dehydrated in ethanol and embedded in epoxy resin. Thin sections $(0.5-1 \mathrm{Lm})$ were stained with toluidine blue to identify the location of AV node. Ultrathin sections $\left(600 \mathrm{~A}^{\circ}\right)$ were mounted on the copper grids and stained with uranyl acetate and lead citrate and were examined with a Philips CM-10 electron microscope, and electromicrographs were prepared.

\section{Results}

Purkinje fibers in the ostrich heart are large specialized cardiac muscle fibers. They have a much greater diameter than normal muscle fiber, about 5.5-16 $\mu \mathrm{m}$. The arrangement of the component in P-fiber is different from cardiac muscle fibers. The great part of the fiber is composed of clear, structure less sarcoplasm, and the myofibrils tend to be confined to a thin ring around the periphery of the cells. They have one or more large nuclei centrally located within the fiber (Figure 1). P-fiber in the heart of the ostrich was distributed widely. Throughout the endocardial layers, particularly the subendocardial layer, numerous P-fibers, arranged in one or more rows, are seen (Figure 2). In the myocardium, between muscles bundles, the P-fibers are seen. Passing outwards from the network of P-fibers lying in the endothelial layer, there are large numbers of conduction fiber tracts. These tracts divide up, passing between the muscle fiber bundles, and eventually the finest divisions of the tracts, single Purkinje fibers, are found within the bundles in close association with the muscle fibers. These fiber tracts are usually found in association with the branches of the coronary arteries (Figure 3). The P-fibers are occasionally seen in epicardial layer but occurs lie in protrusion of epicardium below of the surface of myocardium around coronary arteries. In the right auricle of the ostrich heart, P-fibers are found mostextenely beneath the endocardium as a single fibre or well-developed tracts. These latter are found most frequently in the junction of auricle with right atrium, and macroscopically they are with fibers sheet in this junction (Figure 4).

The conducting system of the heart (sinoatrial node, arterioventricular node his bundle and its branches) consists of these fibers. The structure of P-fiber varies according to the part of conducting system in which they occur. The sinoatrial node is composed of P-fibers and intermediate fibers (the fibers which, in appearance, are intermediate between Pfibers and cardiac muscle fibers). P-fibers are located in the peripheral region of this node and passing away from it. In the initial stages of their passage away from the node, they have a thick connection tissue sheet (Figure 5).

The atrioventricular node is composed of fibers which resemble P-fiber more closely than the myocardial muscle fibers. Posteriorly, the AV-node narrows down somewhat and 


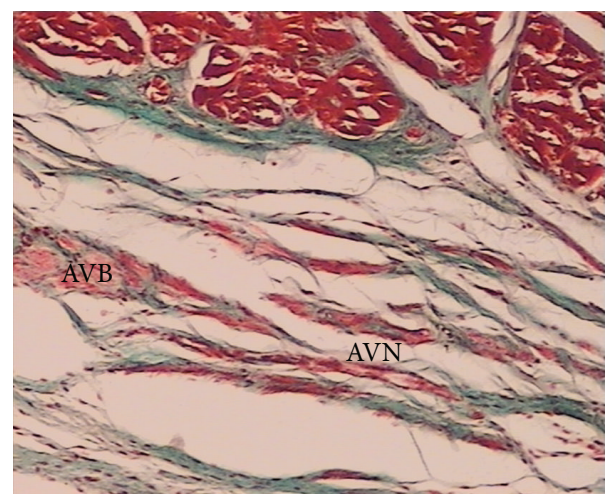

FIGURE 6: Indicative junction of the arterioventricular node (AVN) and arterioventricular bundle (AVB) in the male ostrich heart. Green Masson's Trichrome.

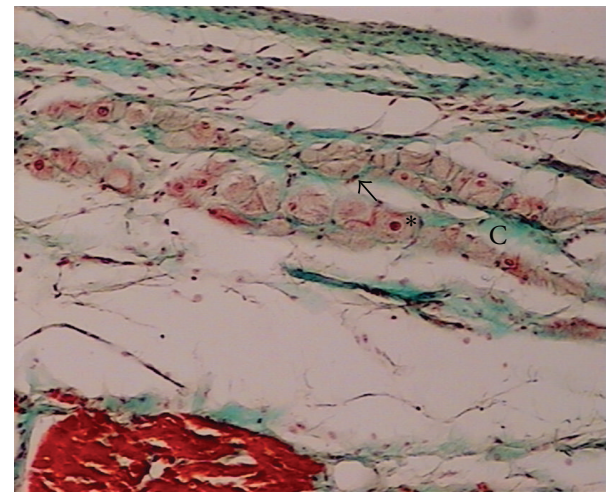

FIGURE 7: Photomicrograph from the microscopic location of the Purkinje cells $\left({ }^{*}\right)$ in arterioventricular of bundle (AVB) in the male ostrich heart. C-collagen fibers, arrow-fibroblast; Green Masson's Trichrome.

continues as the arterioventricular (His) bundle (Figure 6). This bundle itself is composed of a large number of Pfibers. Three bundle branches (right/left and recurrent) are consisting of P-fibers which are arranged as a cord (Figure 7).

The moderator bands, which are found in the right and left ventricle of the ostrich's heart, consist of only dense irregular connective tissue, and the Purkinje cells fill the core of moderator bands. There was cell-to-cell communication between Purkinje fibers within the bundle. The Purkinje cells were surrounded by connective tissue sheath (Figure 8).

The thick muscular stalk attached the peripheral edge of the muscular right AV value to the arterio-ventricular septum and rough parietal wall of the ventricle. Histologically it is composed of Purkinje fibers (Figure 9).

With the electron microscopy, the P-cell is easily distinguished. The main distinction feature is the lack of electron density and having a light appearance, due to the absence of organized myofibrils. P-cells usually have two nuclei with a mass of short, delicate microfilaments scattered randomly in the cytoplasm; they contain short sarcomeres and myofibrillar insertion plaque. They do not have T-tubules (Figure 10).

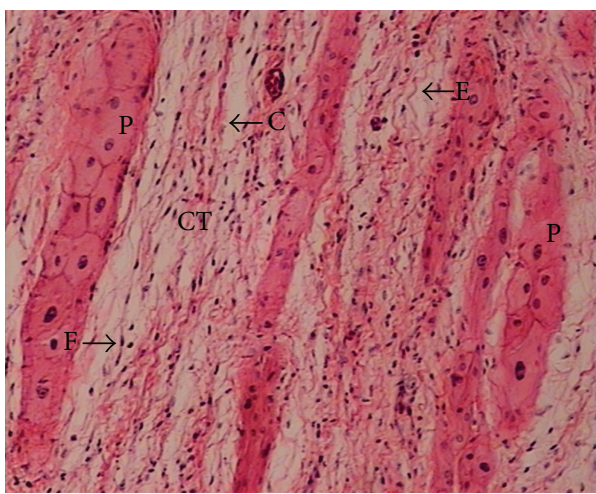

FIGURE 8: Photomicrograph from the microscopic location connecting the left stalk in the connecting area to atrioventricular valve. CT-connective tissue mass, P-Purkinje cells, E-elastic fibers, $\mathrm{F}$-fibroblast cell, $\mathrm{C}$-collagen fibers, $\mathrm{P}$ - parietal wall of the right ventricle; $\mathrm{H} \& \mathrm{E}$.

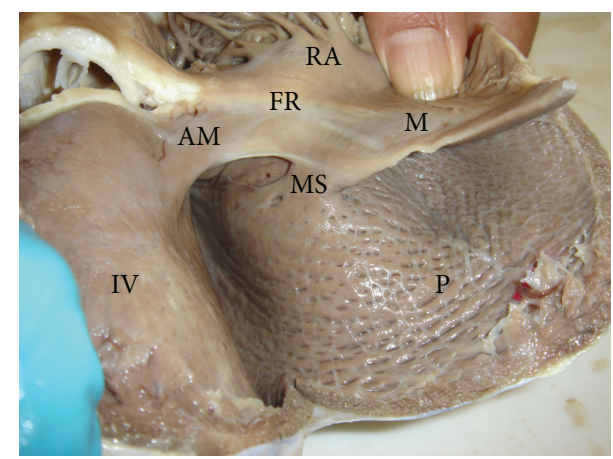

FIGURE 9: The heart of male ostrich, showing the anatomical location of the atrioventricular valve. FR-fibrous ring, RA-right atrium, IV-interventricular septum, M-right muscular valve, MS—-muscular stalk, AM—connect the left stalk.

\section{Discussion}

The distribution of Purkinje fibers has been studied in various mammals. In mammals, the Purkinje network is distributed in the subendocardial connective tissue in ventricle. These networks conduct the cardiac excitation from right and left his bundle to the myocardium. In human and dogs, the Purkinje cell in the network is cylindrical or fusiform in shape and arranged in a parallel pattern [9]. In ungulates (sheep and goat), the chain of Purkinje cells was larger than myocytes, and 2-8 oval cells formed these network. The cells connect to each other by desmosomes and gap junction. These cells are covered by a thick sheath of reticular fibers [10]. In rat and mice, Purkinje cells were very similar to ventricular myocytes even a little smaller. They are cylindrical in shape and organized in parallel pattern, continuing with ventricular myocytes in the endocardium [11].

Various aspects of the histochemistry of Purkinje fibers have been studied by Getty [12] and Gossrau [13]. The observations of DiDio [14], Hirako [15], and Sommer and Johnson [16] on the general morphology of the ordinary and Purkinje cells of the fowl heart have been confirmed. The Purkinje cells 


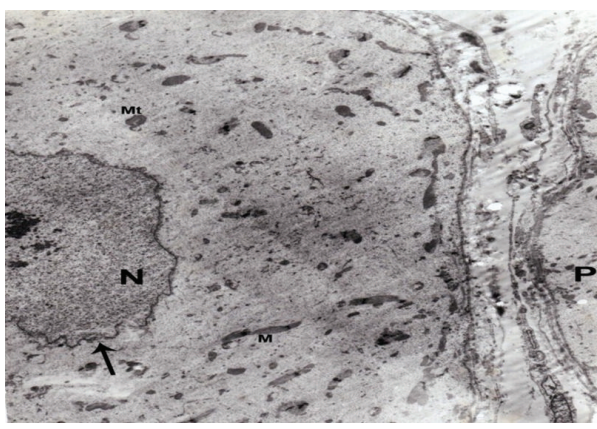

(a)

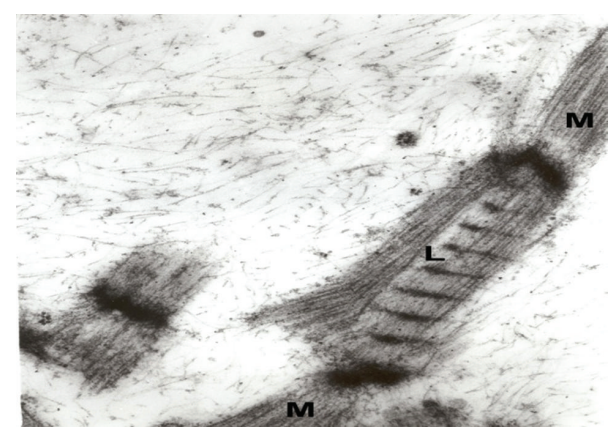

(b)

Figure 10: (a) Electromicrograph of two P cells (P) represents the folded membrane (arrow), nucleus (N), myofibrils (M), and mitochondrial (Mt). (b) Electromicrograph part of the P cell, showing leptomer (L), along myofibril (M).

of the fowl are similar in almost all aspects to those of mammals. They do not have step-like intercalated discs but have irregularly arranged areas of membrane apposition, which possess desmosomes, myofibrillar insertion plaques, and large pentalaminar nexuses. No transverse tubular system is present, and the sarcoplasmic reticulum is poorly developed. The few myofibrils are irregularly arranged. The Purkinje cells have been observed in this study to contain rounded aggregations of leptomeres. Leptomeres have previously been described by Hirako [15] who suggested that they represented an aberrant form of muscle fibril arising during development. This is unlikely since they are present in almost all Purkinje cells.

It seems reasonable to assume that they are associated with myofibrillar formation or destruction since they are seen in association with large masses of disorganized filaments and also in continuity with apparently normal myofibrils. The conducting system consists of the sinoatrial node, the atrioventricular node and bundles, and highly complex network of fine bundles and tracts [16]. Although SA node has been demonstrated in other birds, there is still some doubt as to its position and even its presence as a discrete node in birds [17]. Concluded from physiological evidence that an SA node was present near the termination of the right precaval vein. The node in an ostrich heart is composed of fibers, which in appearance are intermediate between muscle fibers and true Purkinje fibers. Peripherally within the node and passing away from it are several true P-fibers. The distribution of P-fibers within the auricles in ostrich heart is similar to that described by Davis [18] for the pigeon. Prakash [19] has stated that the atria are devoid of P-fibers. In our study, they are found within the myocardium in association with blood vessels, and occasionally in the epicardium [20]. Davis [18] stated that the auricular P-fibers stop short at the base of the auricles and that there are no interconnections between them and the reminder of the cardiac conducting system.

In the ostrich, the AV-node lies in the base of the auricular septum. It is very close to the junction of the auricular and ventricular septa. It is composed of fibers which resemble Pfibers more closely than the myocardial muscle fibres and that they are not identical to those of the SA-node. As Prakash [19] reported, the atrioventricular bundle in our study extend deep into the interventricular septum and then bifurcate into right and left limb. The later branch divides up from the network of P-fibers. Prakash's [19] description does not exactly coincide with that of DiDio [14] for the pigeon and swan but resemble more closely to that of Drennan [21] for the Ostrich. Similarly, the description of Yousuf [22] for the heart of passer differs in the basic structure of this part of the conducting system.

One of the features of specific interest in the ostrich heart is the presence of moderator bands in both the right and left ventricles and in different locations. The right ventricle has one tendinous moderator band about the base of the ventricle that extends from the septum to the muscular valve. Also the moderator bands are usually about apex of the right ventricle that extend from septum to parietal wall. In the left ventricle, there were some tendinous moderator bands close to the apex that extend from septum to parietal wall and between trabeculae carneae of parietal wall. The moderator bands tend to prevent over distension and serve as the pathway for the passing of Purkinje fibers across the lumen of the cavity forming a part of the conducting system. Anatomically, the location of the moderator band in the right and left ventricle of the ostrich heart is different from the other animals. There were no papillary muscle in the right ventricle of the ostrich and the moderator band attaches directly to the ventral surface of muscular valve from interventricular septum.

Since in human $[23,24]$ the moderator band extends between interventricular septum and ventricular free wall and in domestic animals [25] and ungulates [26] these bands extend from interventricular septum to the papillary muscle and there is no connection to the vulvar cusps. In the Ostrich left ventricle, despite the presence of papillary muscle, these bands have no connection to them. Histologic structure of moderator band showed that they have muscular tissue in various proportions with connective and conductive tissue [27]. It is similar to that of the human [28], ungulate [26], sheep [24, 29] and goat [24] hearts but in the carnivores, a real moderator band was never found [26]. Whatever is the size and shape, the moderator band must be regarded as the shortest pathway from interventricular septum to the free wall of left and right ventricle in the ostrich and other animals. The Purkinje fibers are large in size and similar in 
most cellular characteristics in ostrich and dog [30], but in the ostrich, there is no perinuclear clear area. There is a little glycogen in these cells, but in human and mammals these cells are rich in glycogen [4]. The Purkinje fibers are organized into the bundle with cell-to-cell communication and little lateral communication. In the ostrich, there is a sheath of connective tissue around the Purkinje cells, but in human and mammals there is no fibrous sheath around these cells [25]. This organization of the bundle fibers increases the spread of propagated impulses and inhibits the transverse spread. In the right ventricle, there is one musculotendinous moderator band about the base of the ventricle, which extends from the interventricular septum to the muscular stalk of the muscular valve. It was single and sometimes branched [4].

\section{Acknowledgment}

The authors are grateful to the research council of the Shiraz University for providing financial assistance.

\section{References}

[1] O. Eliška, "Purkynje fibers of the heart conduction systemhistory and the present time," Ćasopis Lekaru Ceskych, vol. 145, no. 4, pp. 329-335, 2006.

[2] S. Tawara, Das Reizleitungssystem des Saugetierhezens, Verlag von Gustav Fischer, Jena, Germany, 1906.

[3] B. F. Hoffman, P. F. Cranefield, J. H. Stuckey, and A. A. Bagdanas, "Electrical activity during the P-R interval," Circulation Research, vol. 8, pp. 1200-1211, 1960.

[4] L. C. Armiger, F. Urthaler, and T. N. James, "Morphological changes in the right ventricular septomarginal trabecula (false tendon) during maturation and ageing in the dog heart," Journal of Anatomy, vol. 129, no. 4, pp. 805-817, 1979.

[5] S. Forsgren, L. E. Thornell, and A. Eriksson, "The development of the Purkinje fibre system in the bovine fetal heart," Anatomy and Embryology, vol. 159, no. 2, pp. 125-135, 1980.

[6] S. Forsgren and L. E. Thornell, "The development of Purkinje fibres and ordinary myocytes in the bovine fetal heart. An ultrastructural study," Anatomy and Embryology, vol. 162, no. 2, pp. 127-136, 1981.

[7] M. Tadjalli, S. R. Ghazi, and P. Parto, "Gross anatomy of the heart in Ostrich (Struthio camelus)," Iranian Journal of Veterinary Research, vol. 10, no. 1, pp. 21-27, 2009.

[8] L. G. Luna, Manual of Histologic Staining Methods of the Armed Forces Institute of Pathology, American Registry of Pathology, New York, NY, USA, 3rd edition, 1968.

[9] P. F. Cranefield, A. L. Wit, and B. F. Hoffman, "Conduction of the cardiac impulse. 3. Characteristics of very slow conduction," Journal of General Physiology, vol. 59, no. 2, pp. 227-246, 1972.

[10] T. Shimada, T. Ushiki, and T. Fujita, "Purkinje fibers of the heart," Shinyaku to Chiryou, vol. 42, pp. 11-13, 1992.

[11] Sawazaki, Hikaku Sinzougaku, Asakura Shoten, 1985, (Japanese).

[12] R. Getty, Sisson and Grossman's, the Anatomy of the Domestic Animals, WB Saunders, 5th edition, 1975.

[13] R. Gossrau, "The impulse conducting system of the birdshistochemical and electron microscopical investigations," Histochemie, vol. 13, no. 2, pp. 111-159, 1968.
[14] L. J. DiDio, "Myocardial ultrastructure and electrocardiograms of the hummingbird under normal and experimental conditions," Anatomical Record, vol. 159, no. 4, pp. 335-352, 1967.

[15] R. Hirako, "Fine structure of Purkinje fibers in the chick heart," Archivum Histologicum Japonicum, vol. 27, no. 1, pp. 485-499, 1966.

[16] J. R. Sommer and E. A. Johnson, "Cardiac muscle-a comparative ultrastructural study with special reference to frog and chicken hearts," Zeitschrift für Zellforschung und Mikroskopische Anatomie, vol. 98, no. 3, pp. 437-468, 1969.

[17] E. Mangold and T. Kato, "Zur vergleichenden Physiologie des His'schen Bündels," Pflügers Archiv, vol. 160, pp. 91-131, 1914.

[18] F. Davis, “The conducting system of the bird's heart," Journal of Anatomy, vol. 64, pp. 129-146, 1930.

[19] R. Prakash, "The heart and its conducting system in the common Indian fowl," Proceedings of the National Institute of Sciences of India, vol. 22, pp. 22-27, 1956.

[20] R. C. Truex, Comparative Anatomy and Functional Consideration of the Cardiac Conducting System, Elsevier, Amsterdam, The Netherlands, 1961.

[21] M. R. Drennan, “The auriculo-ventricular bundle in the bird's heart," British Medical Journal, vol. 1, pp. 321-322, 1927.

[22] N. Yousuf, "The conducting system of the heart of the house sparrow, Passer domesticus indicus," Anatomical Record, vol. 152, no. 3, pp. 235-249, 1965.

[23] A. K. Abdulla, A. Frustaci, J. E. Martinez, R. A. Florio, J. Somerville, and E. G. J. Olsen, "Echocardiography and pathology of left ventricular "false tendons"', Chest, vol. 98, no. 1, pp. 129-132, 1990.

[24] M. Deniz, M. Kilinç, and E. S. Hatipoglu, "Morphologic study of left ventricular bands," Surgical and Radiologic Anatomy, vol. 26, no. 3, pp. 230-234, 2004.

[25] R. Depreux, H. Mestdagh, and M. Houcke, "Comparative morphology of the trabecula septomarginalis in terrestrial mammals," Anatomischer Anzeiger, vol. 139, no. 1-2, pp. 24-35, 1976.

[26] D. Lotkowski, M. Grzybiak, D. Kozłowski, K. Budzyn, and W. Kuta, "A microscopic view of false tendons in the left ventricle of the human heart," Folia morphologica, vol. 56, no. 1, pp. 31-39, 1997.

[27] P. Parto, M. Tadjalli, and S. R. Ghazi, "Macroscopic and microscopic studies on maderator bands in the heart of ostrich (struthio camelus)," Global Veterinaria, vol. 4, no. 4, pp. 374-379, 2010.

[28] R. I. Clelland, "Note on a moderator band in the left ventricle and perforate septum ovale in the heart of a sheep," Journal of Anatomy and Physiology, vol. 32, no. 4, p. 779, 1898.

[29] G. E. Sandusky Jr. and S. L. White, "Scanning electron microscopy of the canine atrioventricular bundle and moderator band," American Journal of Veterinary Research, vol. 46, no. 1, pp. 249-252, 1985.

[30] R. C. Truex and W. M. Copenhover, "Histology of the moderator band in man and other mammals with special reference to the conduction system," American Journal of Anatomy, vol. 80, no. 2, pp. 173-201, 1947. 

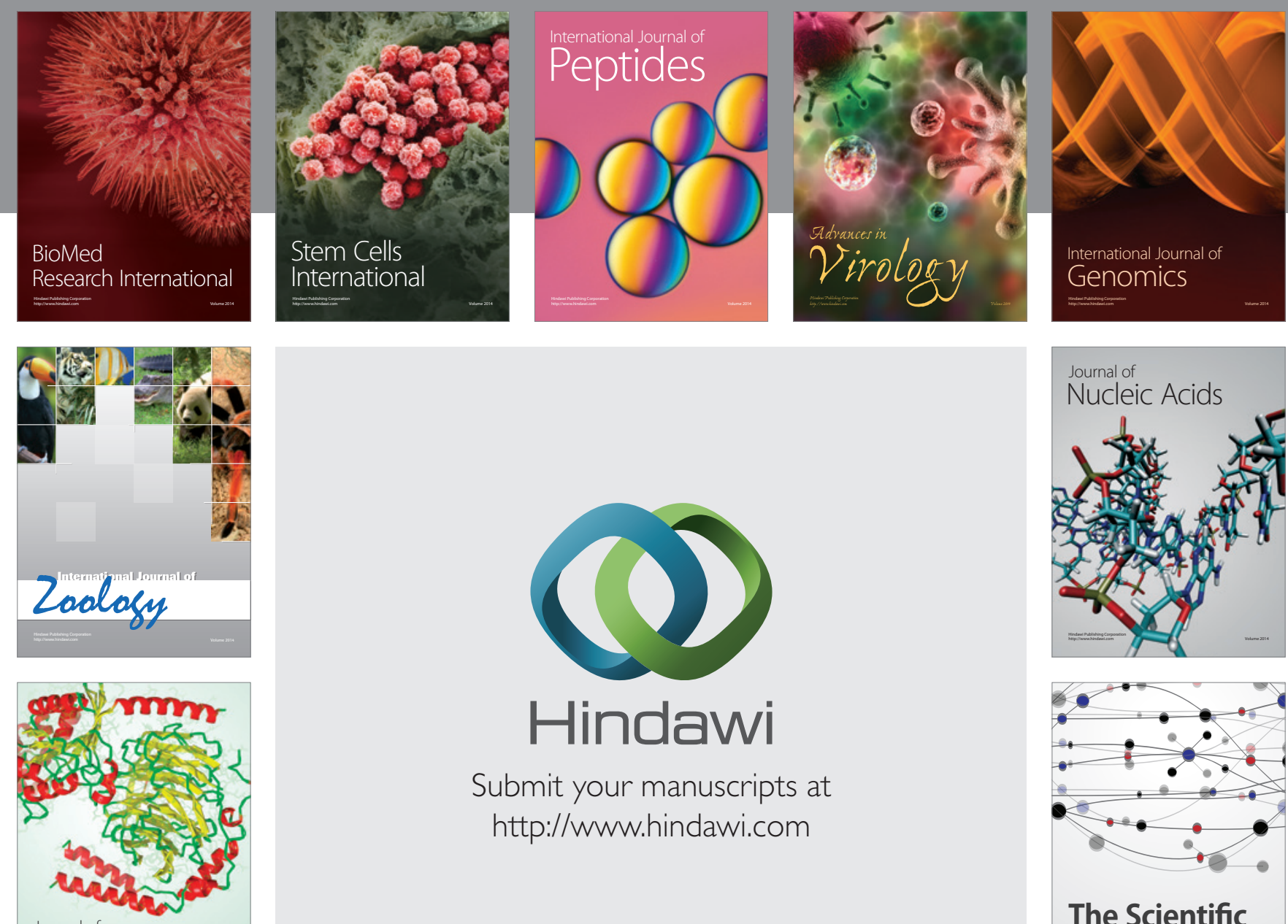

Submit your manuscripts at

http://www.hindawi.com

Journal of
Signal Transduction
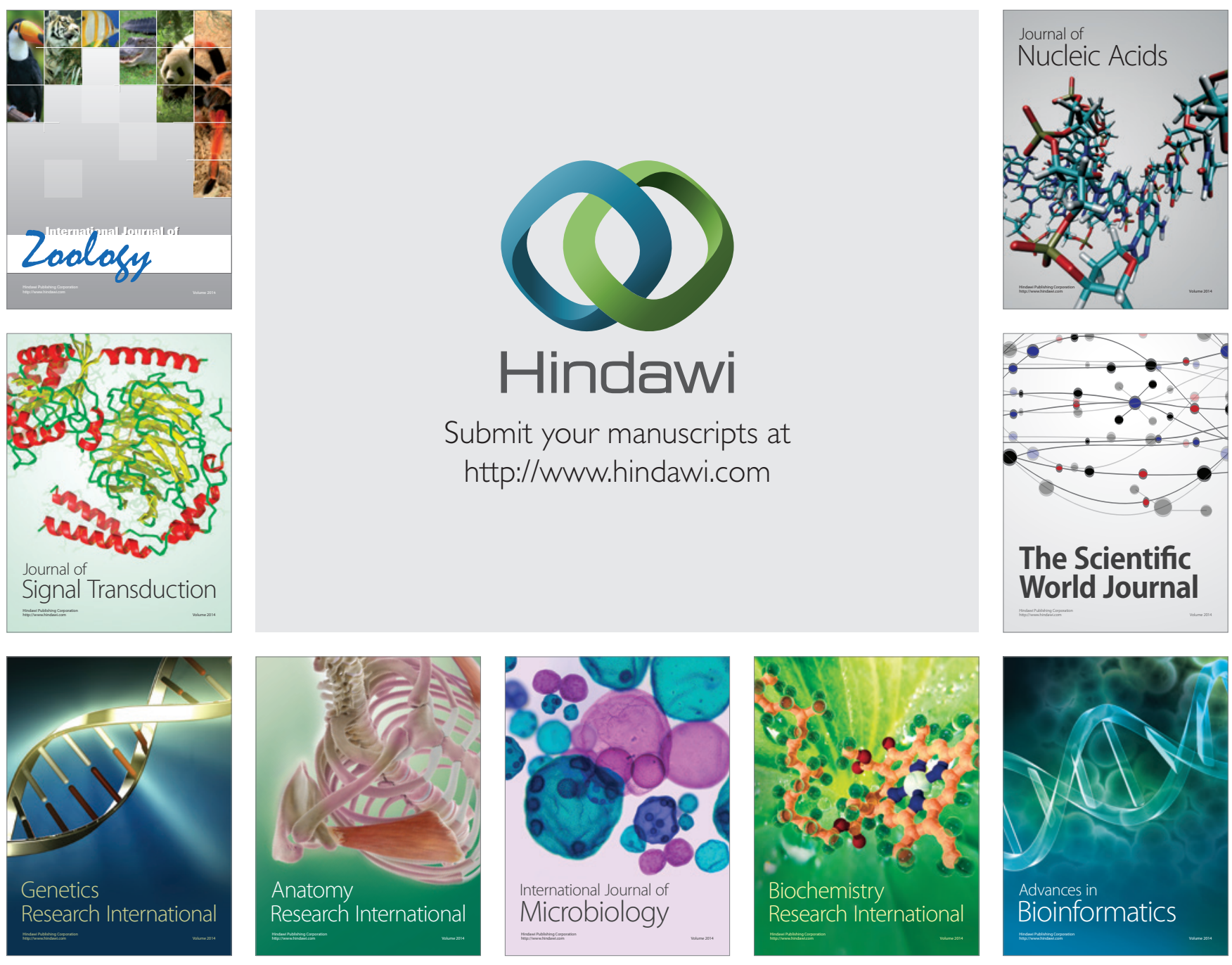

The Scientific World Journal
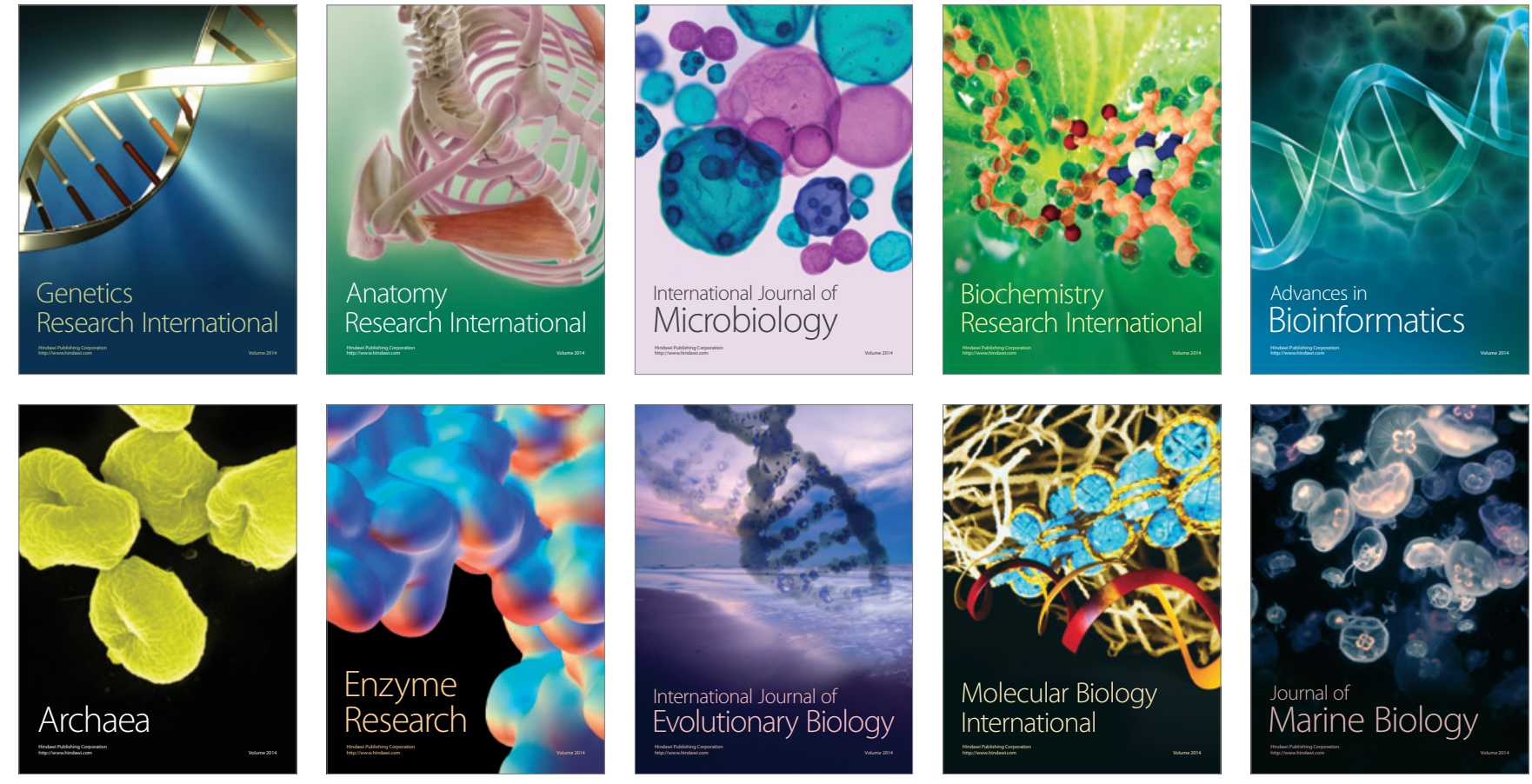